\title{
MAMMOTH PATHOLOGIES AND MEGAFAUNA PREDATION: EVIDENCE FOR OPPORTUNISTIC PREDATION OF THE HEBIOR MAMMOTH
}

KRAMER $^{*}$, Jon M., Georesearch Department, Earth Museum, 3730 Toledo Ave. N., Robbinsdale, MN 55422, U.S.A.; OVERSTREET, David F., Great Lakes Archeological Research Center, 1659 N. Jackson St., Milwaukee, WI 53202, U.S.A.; AUFDERHEIDE, Arthur C., Department of Pathology, School of Medicine, University of Minnesota, 10 University Dr., Duluth, MN 55812, U.S.A.; KRUG, Hollis E., Department of Medicine, Division of Rheumatology, University of Minnesota, Minneapolis, MN 55414, U.S.A.

ABSTRACT: A nearly complete specimen of Mammuthus primigenius was excavated in 1994 from a southeast Wisconsin farm field. Known as the Hebior Mammoth, this specimen has initially been dated at approximately $11,000 \mathrm{BP}$ and exhibits multiple debilitating pathogenic abnormalities in the postcranial skeleton. Evidence of osteomyelitis, chronic septic and degenerative arthritis, and spondyloarthropathy is documented in this specimen. Lithic artifacts found among the bones along with multiple human-induced bone modifications provide clear evidence of Paleoindian butchering by a distinctive, localized culture known as the Chesrow Complex. Examination of the frequency and intensity of the human-induced bone modifications indicate the Hebior specimen had died shortly before butchering. Comparison of this specimen with other contemporary Paleoindian-mammoth sites suggests the Hebior Mammoth was actively hunted. Chesrow Complex differs from regional Clovis/Folsom in that bifaces are typically heat-treated, fashioned from local cherts available in the till rather than exotic materials, and fluting is rudimentary in comparison to such styles as Clovis/Gainey/Folsom. While the appearance of Chesrow dart points is somewhat crude in comparison, they are easily accommodated within the large biface complex so characteristic of Late Pleistocene-Early Holocene technologies. The decision to hunt this animal may have been related to the fact that it had major debilitating health complications resulting from systemic disease. Future investigations of Pleistocene megafauna as prey should more closely scrutinize pathologies of specimens. 